\title{
16. The Inaccessible Archive
}

\section{Ramana}

MV Ramana is the Simons Chair in Disarmament, Global and Human Security and Director of the Liu Institute for Global Issues at the School of Public Policy and Global Affairs, University of British Columbia. He is the author of The Power of Promise: Examining Nuclear Energy in India (Penguin Books, 2012) and co-editor of Prisoners of the Nuclear Dream (Orient Longman, 2003). He is a member of the International Panel on Fissile Materials, the Canadian Pugwash Group, and the Global Council of Abolition 2000. He is the recipient of a Guggenheim Fellowship and a Leo Szilard Award from the American Physical Society.

m.v.ramana@ubc.ca

For the entirety of the educational part of my career, I had never ever thought about going into an archive. Two years after I completed my PhD, I changed my area of research focus from elementary particle physics to thinking about nuclear weapons in India. This was in the mid-1990s, a little before India conducted the 1998 nuclear weapon tests in Pokharan. Some months after my career transition, I started developing an odd feeling, that I was spending most of my time on useless activity. That was an odd feeling, because a key reason for my switch from particle physics was my view that it was completely irrelevant to anything in the real world; thus what I was doing then seemed useless. In contrast, my problem was not that thinking about nuclear weapons seemed useless; it was the fact that I was spending most of my time figuring out things that others - for example, the head of the Indian Atomic Energy Commission - already knew quite well. 
In my previous area of work, I would be working out what might be seen at experiments at, say, the Large Hadron Collider in Switzerland, if the world were to be described by various abstruse particle physics theories called dynamical electroweak symmetry breaking. No one had likely ever wondered about these questions in the specific way I was. Although very few people cared about the answer, I was definitely not reinventing something others already knew. Indeed, if someone knew it, they would have likely published it in some standard academic journal. And I could swallow my pride at having been scooped, and go on to working on something else that was not known to anyone. That was how it was in the world of physics, or most disciplines.

In contrast, when thinking about nuclear weapons in India, I was trying to figure out straight forward questions; one that I have gone back to multiple times over the years is how much plutonium had India produced? That number, I learnt soon enough, was a secret. But it was not a complete secret. If you looked around, you could find estimates. Here is where my background in physics came in useful. For, even if the exact number was a secret, it could be worked out from other technical characteristics: from the power capacities of the main nuclear production reactors, the capacity of the reprocessing plant, and so on. Though these are all publicly known numbers, by themselves these characteristics could only allow me to calculate a maximum value for how much plutonium India could have produced. To get a more accurate figure, one needed to know how efficiently these had operated over the years. How often was the CIRUS nuclear reactor shut down over the years, and for how long? Those numbers, again, 
were secret. Still, over the decades I have tried to come up with the best possible guesses for these based on whatever information is publicly available. ${ }^{1}$

It was in grappling with such questions that the idea of an archive even came into my mind. I could imagine that there was some Department of Atomic Energy (DAE) archive, perhaps at the Bhabha Atomic Research Centre in Trombay, where one could find the performance records for CIRUS, the Dhruva reactor and the Trombay reprocessing plant, neatly sorted out by year. If only I could go through these records systematically, I could calculate the plutonium stockpile as it increased year after year. Or it might give data on releases of various radioactive gases such as krypton on an annual basis, which could be used to estimate how much spent fuel was reprocessed each year, and thus how much plutonium might have been produced each year.

But I could also imagine that this archive, too, will be out of bounds for researchers like me, for the same reason that no one would reveal the amount of plutonium produced in India. While I have not tried to access any such archives, I do know that much less sensitive information is denied.

In 2007, my friend and collaborator JY Suchitra and I petitioned Bharat Nabhikya Vidyut Nigam (BHAVINI), a DAE company, and the Indira Gandhi Centre for Atomic Research (IGCAR), two units involved in designing and constructing the Prototype Fast Breeder Reactor (PFBR) in southern India, using the Right to Information (RTI) Act of 2005, to provide us with the estimated cost of fabricating fuel for the PFBR, the projected cost of reprocessing the irradiated spent fuel that will be generated by the PFBR, and the estimated cost of transporting spent fuel. 
These were the data we wanted to use in our examination of the economics of nuclear power in India, including at the PFBR and its associated facilities. ${ }^{2}$

Both IGCAR and BHAVINI responded pointing to Section 8.1(a) of the RTI Act, which, inter alia, protects "information, disclosure of which would prejudicially affect the sovereignty and integrity of India, the security, strategic, scientific or economic interests of the State, relation with foreign State or lead to incitement of an offence." The Public Information Officers at both places stated: "the information you have requested falls within the above definition and therefore, BHAVINI will have no obligation to give the information requested to anyone."

Suchitra and I appealed this decision, pointing out that we were requesting purely economic information and had not sought any technical details on quantities or processes, and that the petitions were in the public interest because the information sought pertained to the cost of electricity that consumers and the tax payers will have to bear. The appeals, including one to the Central Information Commission (CIC), were denied. ${ }^{3}$

If something like transportation costs for radioactive materials is deemed strategic information, too sensitive to be released, what is the likelihood that any archive that deals with plutonium production at the Bhabha Atomic Research Centre will ever be open to me?

The only way I can see that happening is if the Indian government were to give up its nuclear weapons program, as South Africa did at the end of the apartheid regime there. Maybe some day? One lives in hope. 


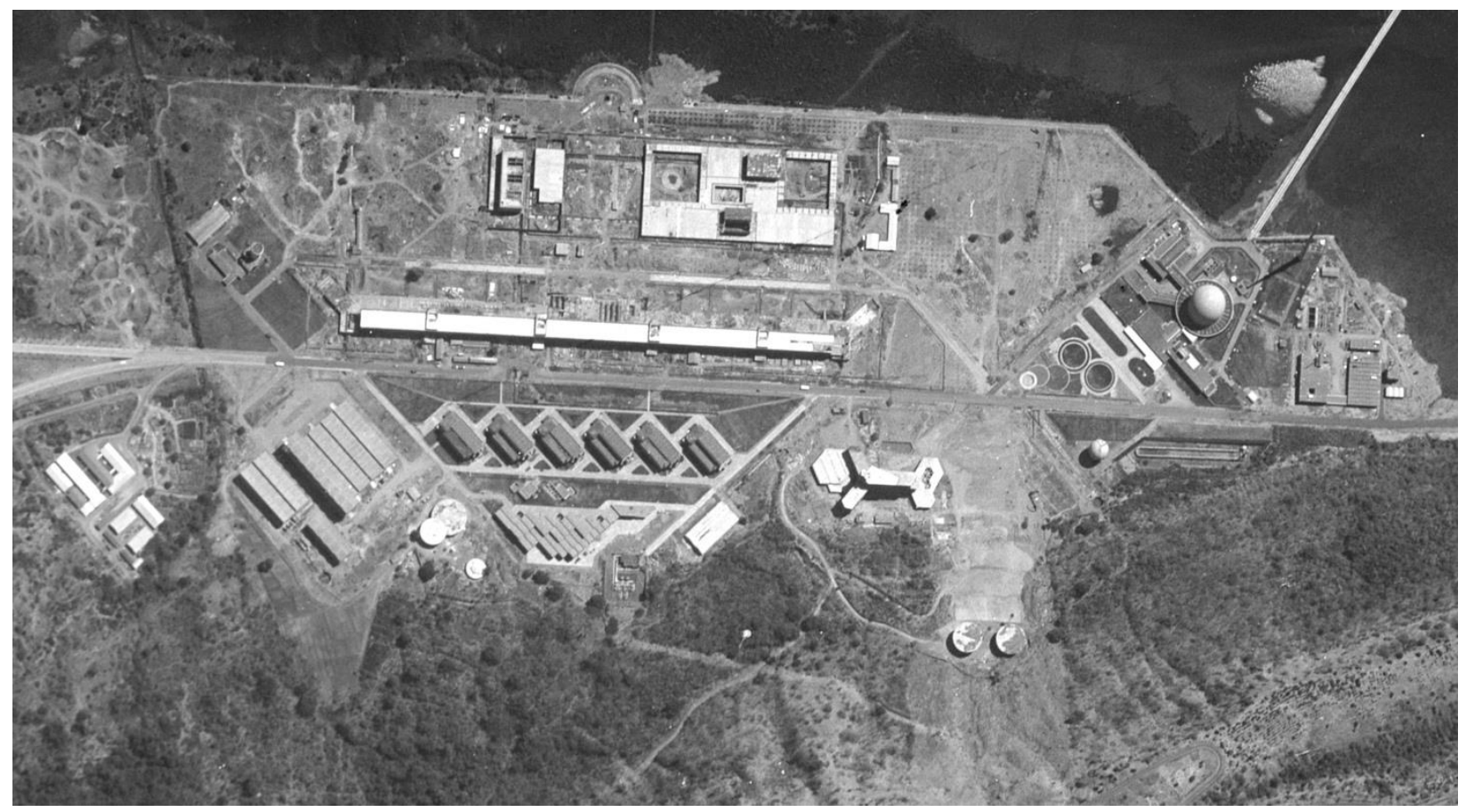

Figure 16: Image of the CIRUS reactor captured by the U.S. $\mathrm{KH}-7$ reconnaissance satellite on February 19, 1966. Though the image was captured in 1966, it was classified for decades. It was only in September 2002 that the US government de-classified all KH-7 imagery-other than images of Israel. (Thus, it was not available to me when I was first starting my exploration of plutonium production in India. Of course, such images do not tell us much about the efficiency with which the reactor would have operated.) The acronym "CIR" stands for Canada India Reactor and the "US" was added after the United States supplied heavy water for the reactor. The reactor is the small bulb like figure on the top right, near the water. The same complex also has a reprocessing plant that is outside the frame in this image. This plant processed the spent fuel generated in the CIRUS reactor to produce the plutonium used in the 1974 nuclear weapon test in Rajasthan. A picture of that blast site can be seen on Robert Anderson's Chapter 17 in this volume, below. The CIRUS reactor was shut down at the end of 2010. (National Reconnaissance Office, Trombay, India, February 19, 1966, KH-7/GAMBIT satellite photograph, U. S. Government, Washington, D.C.

https://nsarchive2.gwu.edu/NSAEBB/NSAEBB186/image05.pdf. Image is in the Public Domain.)

${ }^{1}$ For more on these methodologies, see IPFM, "Global Fissile Material Report 2010," (Princeton: International Panel on Fissile Materials, 2010). For the evolution of these estimates, see the International Panel on Fissile Materials website (http://fissilematerials.org/). 
2 This was eventually published as J. Y. Suchitra and M. V. Ramana, "The Costs of Power: Plutonium and the Economics of India's Prototype Fast Breeder Reactor," International Journal of Global Energy Issues 35, no. 1 (2011): 1-23.

3 JY Suchitra and MV Ramana, "Fast Breeder of Expenditure?" Hindustan Times, October 23, 2007. 